\title{
Correlatos Valorativos do Sexismo Ambivalente
}

\author{
Raquel Pereira Belo ${ }^{12}$ \\ Valdiney V. Gouveia \\ Jorge da Silva Raymundo \\ Célia Maria Cruz Marques \\ Universidade Federal da Paraíba
}

\begin{abstract}
Resumo
O presente estudo teve como objetivo principal conhecer em que medida os valores humanos se correlacionam com o sexismo ambivalente e suas dimensões hostil e benévola. Participaram 301 pessoas da população geral de João Pessoa, provenientes de diferentes classes sociais. Suas idades variaram de 18 a 72 anos $(m=29,5 ; d p=11,58)$, sendo a maioria do sexo feminino ( $54,2 \%)$, católica $(56,8 \%)$, solteira (53,2\%) e com curso superior (53,5\%). Estas responderam o Inventário de Sexismo Ambivalente e o Questionário dos Valores Básicos, além de uma lista com 5 perguntas sócio-demográficas. Os resultados podem ser sumarizados como segue: 1) as duas dimensões do sexismo (benévolo e hostil) se mostraram diretamente correlacionadas entre si; 2) os homens mostraram maior pontuação em sexismo hostil do que as mulheres, embora não diferenciassem em termos do sexismo benévolo; 3) os participantes com pouco estudo, com uma religião definida (católica ou protestante) e de classe social baixa se mostraram mais sexistas; e, finalmente, 4) aqueles com maior pontuação nos valores normativos (obediência, religiosidade) apresentaram maior índice de sexismo, enquanto que os que o fizeram nos valores suprapessoais (beleza e conhecimento) obtiveram as menores pontuações nesta forma de expressão do preconceito. Estes resultados corroboram a concepção de que pensamentos, crenças e comportamentos conservadores tendem a promover o sexismo, ao passo que as pessoas orientadas ao universalismo, que são autodirigidas e não se prendem a preceitos específicos, tendem a ser menos sexistas.

Palavras-chave: Sexismo hostil; sexismo benévolo; valores humanos.
\end{abstract}

Value Correlates of Ambivalent Sexism

\begin{abstract}
This study aimed at knowing the extent to which the human values and ambivalent sexism correlated with each other and with both sexism dimensions: hostile and benevolent. A sample of 301 individuals deriving from different social classes of João Pessoa took part in the present study. Their ages ranged from 18 to 72 years old $(m=29.5 ; s d=11.58)$. The sample was composed mostly of women $(54.2 \%)$, catholic $(56.8 \%)$, single (53.2\%) and university graduates (53.5\%). They answered the Ambivalent Sexism Inventory, the Basic Values Questionnaire and a set of demographic questions. The results can be abridged as follows: 1) Both sexism dimensions (hostile and benevolent) correlated with each other; 2) men showed higher scores in hostile sexism than women, although no difference between them was found on benevolent sexism scores; 3 ) participants deriving from lower social classes, with a specific religion (Catholic and Protestant) and less time of study presented higher sexism scores; and 4) those who scored high on normative values (obedience and religiosity) also presented a high score on ambivalent sexism, while the participants with high scores on suprapersonal values (beauty and knowledge) scored lower on this kind of prejudice. These results corroborate the idea that conservative thoughts, beliefs and behavior tend to promote ambivalent sexism. Otherwise, self-directed people who are oriented to universalism and are not attached to specific principles tend to be less sexists.

Keywords: Hostil sexism; benevolent sexism; human values.
\end{abstract}

O patriarcalismo, uma forma de expressão do absolutismo masculino, é uma das estruturas sobre as quais se assentam as sociedades contemporâneas e demonstra, na maioria delas, a capacidade de influenciar relacionamentos interpessoais (Castells, 2000). É um sistema que garante a supremacia social aos homens, concedendo-lhes o controle das instituições econômicas, legais e políticas, com poder estrutural como grupo dominante, delegando às mulheres uma educação voltada predominantemente para a problemática doméstica, responsabilizando-as pelo cuidado da casa, dos filhos e pela satisfação sexual do marido, em decorrência de serem consideradas como intelectualmente menos dotadas. Tal contexto ocasiona uma socialização na qual a representação da masculinidade é associada à responsabilidade pelo sustento da família, enquanto a

${ }^{1}$ Endereço para correspondência: R. Vitória Régia, 160, 54759 140. Camaragibe, PE.E-mail:quelbelo@hotmail.com

O presente estudo compreendeu parte da dissertação de mestrado da primeira autora, sob orientação dos dois seguintes; contou com bolsa do Conselho Nacional de Desenvolvimento Científico e Tecnológico (CNPq). Os autores aproveitam para agradecer a esta instituição. feminilidade está associada à submissão e responsabilidade pelo lar e pela prole (Ferreira, 2000).

A ideologia que suporta este sistema é em grande parte resultante de uma construção cultural que, de acordo com Heilborn (1999), tem a capacidade de conduzir as construções ideológicas / institucionais tanto na época atual como, provavelmente, em direção a novos horizontes, que serão engendrados buscando primordialmente demonstrar as mulheres como um grupo inferior. Tal construção possui um dinamismo tão articulado e uma força progressiva tão constante que acaba parecendo aos indivíduos uma construção universal e natural. Entretanto, partindo-se de uma visão antropológica, observa-se que toda esta construção é o resultado de um sistema de significação que pode ser chamado de cultura ocidental moderna, com a capacidade de moldar a percepção dos sujeitos para aceitarem os fenômenos que ocorrem à sua volta. As conseqüências deste tipo de construção cultural aparecem, de forma visível, nas questões relativas à sexualidade.

Pensar a sexualidade, entretanto, requer ponderação e equilíbrio. Reduzir a sexualidade à natureza representa um ato tão precipitado quanto considerar sua diferença apenas como 
resultado de uma construção histórica, segundo Agacinski (1999). Para este autor, é fundamental levar em conta que, se por um lado a diferença natural entre os sexos é real, por outro, considerar apenas esta naturalidade torna-se insignificante, uma vez que ela só tem sentido quando interpretada no contexto em que está inserida. Por este ponto de vista, a natureza fornece a diferença, mas a leitura de tal diferença é construída e organizada socialmente por cada cultura, sugerindo uma variabilidade considerável na sua explicação. Ressalta-se, neste domínio, que tal diferença ou sua manifestação também é resultante de construções sociais humanas, a exemplo das leis que, em alguns países (Ex.: no Brasil) punem atitudes e comportamentos notórios de discriminação contra grupos minoritários, entre os quais os negros e as mulheres. Neste contexto, as formas tradicionais de preconceito tendem a se modificar, dando lugar a expressões mais sutis (Martínez, 1996); o sexismo aberto e flagrante, por exemplo, tem dado passo a estratégias menos evidentes de discriminação, confundindo-se mesmo com estilos generosos e galanteadores. Estas duas faces da mesma moeda se fundem no que hoje se conhece como sexismo ambivalente (Glick \& Fiske, 1996).

Portanto, é possível assumir que, apesar da diferença entre os gêneros estruturar universalmente as sociedades, os valores e os conteúdos atribuídos a esta diferença são culturalmente variáveis. Este aspecto anima a procurar compreender em cada cultura os correlatos das concepções estereotipadas e do preconceito acerca do gênero feminino, que tem padecido as discriminações de uma sociedade eminentemente patriarcal. Este foi também o mote do presente estudo, cujo objetivo geral compreendeu conhecer a natureza da correlação entre os valores humanos e as dimensões do sexismo ambivalente. Neste sentido, tais construtos demandam maior atenção.

\section{Sexismo Ambivalente}

O processo de formação de impressão, que constitui um conjunto de avaliações afetivas, morais e instrumentais, elaboradas a respeito de uma pessoa, possui a capacidade de orientar o percebedor em suas relações com o meio social. Tal processo, conceituado como estereótipo, representa generalizações a respeito dos indivíduos em função destes pertencerem a algum grupo ou alguma categoria social, sem levar em conta suas características individuais (Camino, 1996). A idéia, por exemplo, de que a mulher deve ficar dentro de casa, por ser o sexo mais frágil, e a divulgação de crenças que defendem ser ela incompetente para as tarefas que dizem respeito às áreas econômica, jurídica e política, refletem uma forma de pensamento estereotipada.

Tais concepções, que delegam à mulher papéis socialmente limitados, são contempladas por Glick e Fiske (1996) no marco da teoria do sexismo ambivalente, sendo conceituado como um conjunto de estereótipos negativos que avaliam as mulheres de forma cognitiva, afetiva e atitudinal em função de seu sexo. Tais expressões refletem mais uma das formas de preconceito existente dentro do contexto social, guiado por idéias como as de que as mulheres, apesar de puras e frágeis, buscam controlar os homens através de seus atributos sexuais.
A ambivalência referente ao sexismo diz respeito à existência de uma construção simultânea de duas ideologias voltadas para a mulher: uma de cunho benévolo e outra de cunho hostil. Os dois tipos de sexismo, hostil e benévolo, são produtos da estrutura relacional entre os sexos, sendo expressos através de idéias como as de que os homens são tipicamente constituídos de mais poder que as mulheres; que homens e mulheres são freqüentemente diferenciados em termos de papel social; e que as relações entre homens e mulheres são condicionadas apenas pela reprodução sexual (Glick \& Fiske, 2001b).

O poder estrutural masculino, o patriarcalismo, possui implicações fundamentais para o conteúdo ideológico hostil e benévolo. Tal sistema, apesar de não ser exatamente universal, é adotado atualmente em diversas culturas, sendo refletido através do domínio masculino prevalente na ocupação de cargos com alto status nas áreas de negócios, governo e instituições religiosas. Portanto, as diferenças de poder existentes entre os sexos, demonstram em grande parte a interiorização da ideologia ambivalente, em conseqüência do estabelecimento ideológico de que o gênero masculino é superior ao feminino. Neste contexto, Glick e Fiske (1996) propõem que a ideologia sexista constitui uma construção refletora de tal pensamento (o patriarcalista), existente em diversas culturas e responsável pelas diferenças de poder entre os sexos nos contextos sócio-cultural (legitimando os papéis e as relações convencionais entre os gêneros) e individual (os homens representando o poder dentro da relação amorosa).

O sexismo ambivalente também representa um reflexo da hostilidade voltada para a mulher, sem negligenciar um aspecto significante: os sentimentos subjetivamente positivos que freqüentemente acompanham a antipatia sexista. Estes sentimentos "positivos" caracterizam as concepções sexistas benévolas, que se expressam através de atitudes de admiração e proteção e, na maioria das vezes, não são consideradas como uma forma de discriminação contra a mulher. Tais concepções são contrastadas com uma considerável saliência das concepções sexistas hostis, estruturadas a partir de uma visão competitiva, que caracteriza as mulheres como controladoras dos homens através da sexualidade ou da ideologia feminista. Neste ponto, vale salientar que não apenas o sexismo hostil é responsável pela discriminação da mulher; o sexismo benévolo, de forma subjetiva, também promove a desqualificação do gênero feminino. Portanto, embora as ideologias hostil e benévola sejam diferentes em sua forma de apresentação, funcionam no contexto cultural como um conjunto de crenças refletoras de um sistema de recompensa e punição que estimula a aceitação da diferença de poder existente entre os sexos.

A ambivalência sentida para com as mulheres não necessariamente apresenta com exclusividade uma ideologia adversária. Na verdade, o que ocorre é uma simultaneidade dos sentimentos ambivalentes, expressos através de estereótipos favoráveis e desfavoráveis, demonstrando serem complementares e guardando entre si uma correlação positiva. Independentemente das formas de expressão, ambos os sentimentos possuem o mesmo impulso primário: o desejo de dominar o gênero feminino. Juntas, as ideologias hostil e benévola constituem uma ideologia de ordem superior, representativa do 
sistema de recompensa e punição, gratificando as mulheres que incorporam os papéis convencionais de gênero (inferior e incapaz de realizar atividades de âmbito intelectual) e punindo as que desafiam seu status quo, já determinado pela sociedade. Tal sistema busca, primordialmente, incentivar as mulheres a permanecerem em seus papéis convencionais (Glick \& Fiske, 2001a).

Glick e Fiske (1996) caracterizam, como idéia central de sua teoria, que ambas as formas de sexismo se encontram estruturadas sobre três tipos de expressão, definidores de um conjunto de crenças nas quais a ambivalência para com a mulher é inerente, a saber: paternalismo, diferenciação de gênero e heterossexualidade.

O paternalismo, concebido como a forma de proceder de um pai para com suas crianças, pode ser expresso tanto através de um paternalismo dominante como de um paternalismo protetor. $\mathrm{O}$ paternalismo dominante representa a face hostil da ideologia sexista, na qual os homens representam a figura de autoridade e dominação. Tal face, por ser defensora da crença de que o homem deve ter mais poder que a mulher, objetiva o domínio sobre o gênero feminino. O paternalismo protetor, por outro lado, propaga a idéia de que as mulheres, por serem frágeis, devem ser protegidas pelos homens.

Apesar da variação entre as culturas na sua forma de encarar os papéis ocupados por homens e mulheres, a diferenciação de gênero representa um dos mais fortes e antigos tipos de identidade grupal. Tal diferenciação também possui duas formas de expressão, construídas em função da hostilidade e da benevolência para com a mulher. A diferenciação de gênero competitiva, representante da ideologia hostil, realiza constantes comparações entre os sexos na busca de elevar a auto-estima masculina e demonstrar que as mulheres são inferiores na dimensão da competência. Entretanto, objetivando caracterizar as mulheres como capazes de exercer papéis complementares aos dos homens, o gênero feminino recebe socialmente alguns estereótipos favoráveis, associados às atividades domésticas e aos cuidados com as crianças. A diferenciação de gênero complementar propõe a idéia de que, enquanto os homens se concentram em sua carreira, as mulheres devem trabalhar em casa, desempenhando os papéis de "objeto" romântico, esposa e mãe.

Finalmente, com a capacidade de criar uma das mais fortes relações entre homens e mulheres na intimidade, a heterossexualidade representa a terceira forma de expressão do sexismo ambivalente. A hostilidade sexual resulta da crença de que a sexualidade das mulheres representa um perigo para os homens, uma vez que os homens se sentem vulneráveis às mulheres em suas relações íntimas. Por outro lado, em função da capacidade das relações românticas inspirarem paixão, devoção e idealização, ambos os sexos buscam a intimidade heterossexual com o parceiro, a fim de alcançarem a verdadeira felicidade.

Atualmente, apesar de já ter sofrido bastantes modificações, de uma forma geral o estereótipo da mulher continua resistindo ao tempo e às culturas. Através das pesquisas realizadas na área dos estereótipos de gênero (Borgida, Locksley \& Brekke, 1981), por exemplo, observa-se uma avaliação quase permanente para ambos os sexos. Isto é, o gênero masculino aparece normalmente como assertivo, ativo, objetivo, racional e competente, em contraste com o modelo da típica mulher, tida como mais passiva, emotiva, submissa, compassiva e irracional, demonstrando uma certa permanência da idéia defensora de uma indiscutível superioridade masculina e a das mulheres como constituindo um grupo com menores capacidades intelectuais. Ashmore (1994, citado em Glick, Diebold, Bailey-Werner \& Zhu, 1997), por exemplo, em suas análises a respeito do sexismo, defende a existência de uma prática inerente, característica dos homens sexistas: a constante categorização das mulheres através de estereótipos, utilizados como um guia na elaboração do trato e das respostas que lhes serão dadas.

Em pesquisa realizada em 19 países, entre os quais figurava o Brasil, contando com uma amostra de 15.000 participantes, entre homens e mulheres, Glick e colaboradores (2000) reconhecem que, embora seja prematuro afirmar a universalidade dos sexismos hostil e benévolo, na maioria dos países constituintes do estudo foi possível identificar uma reprodução da ideologia sexista ambivalente. Isso foi notado, principalmente, no que se refere à tendência das mulheres, em comparação com os homens, de rejeitarem as concepções sexistas hostis e aceitarem as sexistas benévolas. Esta última tendência é provavelmente resultado de supostas "vantagens" obtidas pelas mulheres, uma vez que o sexismo benévolo promove um sistema social que, respeitandose as diferenças de gênero, asseguram-lhes proteção, admiração e afeição por parte dos homens. Portanto, a adoção deste tipo de sexismo funcionaria, no caso das mulheres, como uma forma provável de auto-defesa naquelas culturas que convivem com índices elevados de sexismo hostil.

Os achados antes descritos foram também observados em outros estudos. Por exemplo, Glick e Fiske (1996), considerando uma amostra de 2.250 participantes, observaram que, de forma geral, enquanto os homens demonstraram atitudes ambivalentes para com as mulheres, estas apresentaram uma menor ambivalência por mostrarem claramente uma maior aceitação da ideologia sexista benévola. Formiga, Gouveia, Maia e Santos (2002), com cerca de 200 estudantes universitários com idades variando entre 20 e 56 anos, verificaram que os homens apresentaram maior sexismo hostil e as mulheres maior sexismo benévolo.

Em resumo, percebe-se que existe por parte do gênero feminino uma aceitação aos tratos sexistas benévolos e uma rejeição aos sexistas hostis. Contrariamente, os homens demonstram comportamentos sexistas ambivalentes, isto é, apresentam-se ao mesmo tempo como sexistas hostis e benévolos. Embora estas sejam tendências gerais, é possível que variem em função de características individuais ou inclusive de princípios-guia assumidos por homens e mulheres. Neste sentido, consideram-se aqui os valores humanos como prováveis explicadores do sexismo, sugerindo que se defina o marco conceitual adotado.

\section{Valores Humanos}

Os valores, como entendidos por Rokeach (1973), representam o resultado da cultura, da sociedade e da personalidade, apresentando o poder de influenciar atitudes e comportamentos. Funcionam também como padrões de conduta, no sentido de terem inerentes em sua estrutura a capacidade de posicionar o indivíduo diante de princípios sociais e das demais pessoas, possibilitando avaliar, julgar 
e censurar a si mesmo e aos outros. Portanto, considerando o vínculo do sexismo com o contexto cultural, é possível que os valores compreendam elementos determinantes para se compreender a manifestação deste tipo de preconceito.

Apesar de existirem diferentes modelos teóricos sobre os valores, desde a Psicologia e considerando como elementos de sua origem as necessidades, estes apresentam ao menos cinco características que são comuns na literatura (Schwartz \& Bilsky, 1987): 1) compreendem uma crença; 2) pertencem a fins desejáveis; 3) transcendem situações específicas; 4) guiam a seleção ou avaliação de comportamentos, pessoas e sucessos e; 5) podem ser ordenadas por sua importância relativa a outros valores, para formar um sistema de prioridades valorativas.

Certamente, Milton Rokeach e Shalom H. Schwartz são os autores mais representativos desta abordagem dos valores humanos. Seus modelos teóricos são complementares e podem mesmo ser resumidos na proposta que fez este último. Schwartz (2001) propõe um modelo com 10 tipos motivacionais, que representam três tipos de interesses: individuais (autodireção, estimulação, hedonismo, poder e realização), mistos (segurança e universalismo) e coletivos (tradição, conformidade e benevolência). Estes tipos motivacionais conformam uma estrutura circular que reflete compatibilidades e conflitos; aqueles tipos de valores adjacentes (Ex.: realização e poder) refletem compatibilidade, enquanto que os em lados opostos (Ex.: estimulação e conformidade) expressam conflito. Apesar da adequação deste modelo teórico em diversos países (Schwartz \& Sagiv, 1995), a medida dele derivado é relativamente extensa, contando com 56 itens, e tem sido questionada a derivação do conjunto de valores específicos, alguns sendo obtidos da lista intuitiva apresentada por Rokeach (1973), e outros não apresentando uma fonte específica; igualmente não se identifica uma teoria inequívoca das necessidades de onde foram derivados os valores (Molceperes, 1994).

Frente a este contexto, apesar destas duas teorias merecerem atenção, no presente estudo se optou por um modelo mais parcimonioso, que indica um conjunto de 24 valores (Gouveia, 1998), que tiveram origem na lista de necessidades proposta por Maslow (1954/1970). Gouveia (1998) não assumiu completamente os pressupostos de Maslow, mas somente à referência a sua lista de necessidades, aceitando que o homem é um ser benévolo, apresentando unicamente necessidades positivas. Seguindo esta orientação, propôs definir os valores como categorias de orientação, consideradas desejáveis, baseadas nas necessidades humanas e nas pré-condições para satisfazê-las, adotadas por atores sociais, podendo variar sua magnitude e seus elementos constitutivos. O conjunto de valores deste modelo pode ser representado através de três critérios de orientação, cada um subdividido em duas funções psicossociais, como segue:

Valores Pessoais - os indivíduos que assumem estes valores normalmente mantêm relações pessoais contratuais, procurando obter vantagens e lucros, priorizando seus próprios interesses. Os valores desta orientação, indicados a seguir entre parênteses, são agrupados em duas funções psicossociais: Valores de Experimentação: dizem respeito à descoberta e apreciação de novos estímulos, ao enfrentamento de situações arriscadas e à procura de satisfação sexual (emoção, estimulação, praz̧er e sexual); e Valores de Realização: além da experimentação de novos estímulos, o homem também tem o desejo constante de auto-cumprimento e um sentimento de ser importante e poderoso ao ponto de possuir identidade e espaço próprios (autodireção, êxito, poder, prestígio e privacidade);

Valores Centrais - indicam o caráter central ou adjacente dos valores, sendo compatíveis com os valores pessoais e sociais. Subdividemse em: Valores de Existência: para as pessoas que adotam estes valores, o que interessa primordialmente é garantir a própria existência orgânica, com ênfase na existência do indivíduo e não na individualidade pessoal. Esta característica faz com que sejam compatíveis com os valores pessoais e sociais, levando-os a serem importantes para os indivíduos em ambiente de escassez econômica sem colocar em risco a harmonia social (estabilidade pessoal, saúde e sobrevivência); e Valores Suprapessoais: estes valores descrevem alguém maduro, com preocupações menos materiais, não sendo limitados a características descritivas ou específicas para iniciar uma relação ou promover benefícios. Neste contexto, os indivíduos tentam atingir seus objetivos independentemente do grupo ou condição social, enfatizando a importância de todas as pessoas e não apenas daqueles que compõem o próprio grupo (beleza, conbecimento, justiça social e maturidade);

Valores Sociais - os indivíduos que assumem estes valores se apresentam direcionados aos outros, comportam-se como alguém que gosta de ser considerado, que deseja ser aceito e integrado no grupo de pertença, mantendo a harmonia entre os atores sociais em um contexto específico. Este critério de orientação é constituído pelos seguintes grupos de valores: Valores Normativos: os indivíduos que se identificam com este grupo de valores geralmente enfatizam a vida social, a estabilidade do grupo e o respeito aos símbolos e padrões culturais prevalecentes durante anos (obediência, ordem social, religiosidade e tradição); e Valores Interacionais: a focalização do indivíduo aparece voltada para o destino comum e a complacência, com o interesse consistindo em ser amado e ter uma amizade verdadeira, com uma vida social ativa (afetividade, apoio social, convivência e honestidade).

A partir deste marco teórico, buscar-se-á conhecer as relações entre os valores básicos e o sexismo ambivalente. Apesar da eminente relação destes construtos, nenhum estudo empírico foi encontrado na literatura brasileira. Este aspecto dificulta precisar as hipóteses a respeito, porém não as impede. Conforme estudos prévios, valores que acentuam o conservadorismo e o cumprimento com normas sociais promovem o preconceito, enquanto que aqueles cujas idéias centrais são de universalismo, igualdade e transcendência o inibem (Heaven \& Oxman, 1999; Vera \& Martínez, 1994).

\section{Método}

\section{Delineamento e Hipóteses}

Esta pesquisa é de tipo correlacional, considerando como variável critério a pontuação dos participantes na medida de sexismo ambivalente. De acordo com o descrito na introdução, as seguintes hipóteses foram formuladas:

Hipótese 1. As concepções sexistas hostil e benévola estarão diretamente correlacionadas entre si.

Hipótese 2. Os homens apresentarão maior média de sexismo hostil do que as mulheres. 
Hipótese 3. A pontuação total na medida de sexismo estará diretamente correlacionada com a função psicossocial dos valores normativos.

Hipótese 4. A pontuação total na medida de sexismo estará inversamente correlacionada com a função psicossocial dos valores suprapessoais.

A primeira hipótese parece evidente: se os sexismos hostil e benévolo são realmente duas versões de um mesmo sentimento preconceituoso (Glick \& Fiske, 1996), deveriam se correlacionar diretamente. No caso da segunda, tem-se constatado que, embora homens e mulheres possam apresentar pontuações elevadas de sexismo benévolo, estas são menos prováveis endossar o sexismo hostil (Formiga \& cols., 2002; Glick \& cols., 2000). A terceira e quarta hipóteses tomam como referência a pontuação total de sexismo, sendo sua justificativa respaldada em dois aspectos: 1 ) não foram encontrados estudos empíricos sobre a relação dos valores com as dimensões específicas de sexismo hostil e benévolo; e 2) a presumível correlação entre estas duas dimensões. De acordo com os estudos sobre preconceito e valores (Heaven \& Oxman, 1999; Vera \& Martínez, 1994), é coerente assumir que a pontuação total do sexismo se correlacione diretamente com a função psicossocial normativa, que acentua os valores de obediência, tradição, religiosidade e ordem social, e o faça negativamente com a suprapessoal, cuja ênfase é sobre os valores justiça social, maturidade, beleza e conhecimento.

\section{Amostra}

O presente estudo contou com a participação de 301 pessoas da população geral da cidade de João Pessoa, sendo 163 mulheres $(54,2 \%)$ e 138 homens $(45,8 \%)$, com idades compreendidas entre 18 e 72 anos $(m=29,5 ; d p=11,58)$. A maioria dos participantes indicou ser católica (56,8\%) e solteira (53,2\%); entre os que não se encontravam casados ou mantinham um relacionamento afetivo estável, a maioria tinha um namoro fixo $(62,1 \%)$. Além disto, indicaram majoritariamente estudar $(55,8 \%)$, cursar ou ter cursado Universidade $(53,5 \%)$ e trabalhar $(55,5 \%)$. Em relação à classe sócio-econômica, de acordo com a classificação de Lopes de Andrade (2001) que considera os bairros de residência dos participantes, estes se distribuíram do seguinte modo: classe baixa $(n=87)$, classe média $(n=100)$ e classe alta $(n=104)$.

\section{Instrumentos}

Os participantes responderam um bloco de perguntas, constando de três partes, a saber:

Inventário de Sexismo Ambivalente - ISA. Este instrumento é composto por 22 itens, respondidos em uma escala de cinco pontos, tipo Likert, com os seguintes extremos: 1=Discordo Totalmente e $5=$ Concordo Totalmente. Tais itens avaliam os estereótipos assumidos pelos gêneros masculino e feminino, em função de duas dimensões do sexismo: hostil e benévolo. Cada uma destas dimensões possui formas próprias de expressão de sexismo para com a mulher: no caso do sexismo hostil, envolve o paternalismo dominante (Ex.: As mulheres tentam ganhar poder controlando os homens), a diferenciação do gênero (Ex.: As mulheres se ofendem muito facilmente) e a heterossexualidade (Ex.: Existem muitas mulheres que, para chamar a atenção de um homem, primeiro se insinuam sensualmente e depois rejeitam seus avancos ou cantadas). No caso do sexismo benévolo, também são apresentados itens aos três tipos de ideologia: paternalismo protetor (por exemplo, Em caso de grandes ou pequenos acidentes, as mulheres devem ser resgatadas antes que os homens), diferenciação de gênero complementar (Ex.: Muitas mulheres se caracterizam por uma pureza que poucos homens possuem) e intimidade heterossexual (Ex.: Todo homem deve ter uma mulher a quem amar). Este instrumento foi elaborado originalmente em língua inglesa por Glick e Fiske (1996), tendo sido adaptado ao contexto brasileiro por Formiga e colaboradores (2002). A maior pontuação indica maior nível de sexismo.

Questionário dos Valores Básicos. Esta medida se compõe de 24 itens, tendo sido sugerida por Gouveia (1998). Cada um dos itens é constituído por valores específicos e se apresentam estruturados com duas frases que explicitam seu conteúdo. Ex.: justica social (Lutar por menor diferenca entre ricos e pobres; permitir que cada indivíduo seja tratado como alguém valioso); afetividade (Ter uma relação de afeto profunda e duradoura; ter alguém para compartilhar seus êxitos e fracassos). Utilizando uma escala de sete pontos, com os extremos $1=$ Totalmente não Importante e 7=Extremamente Importante, o respondente indica o grau de importância que cada um destes valores tem como um princípio-guia em sua vida. Além disso, ao final desta etapa o respondente é solicitado a indicar quais dos 24 itens é para ele o mais e o menos importante de todos, que recebem os pesos 8 e 0 , respectivamente. Maia (2000) apresenta provas da adequação psicométrica desta medida.

Dados Sócio-Demográficos. Além dos instrumentos anteriormente descritos, elaborou-se uma lista com as seguintes perguntas: sexo, religião (católica, evangélica, sem religião ou outra), idade, escolaridade (ensino fundamental, ensino médio ou ensino superior) e classe social dos participantes. No caso desta variável, foi operacionalizada a partir do seu bairro de residência, segundo a classificação elaborada por Lopes de Andrade (2001).

\section{Procedimentos}

Os questionários foram aplicados em visitas às residências dos potenciais participantes e de abordagens em lugares públicos, como ruas e shoppings. A todos era dito que sua participação deveria ser voluntária, sendo garantido o sigilo das suas respostas uma vez que os dados seriam tratados coletivamente. Também era explicado que não existiam respostas certas ou erradas, e que apenas deveriam apresentar o máximo de sinceridade, sendo necessários, em média, 25 minutos para responder a todo o questionário.

\section{Resultados}

\section{O Sexismo Ambivalente entre Homens e Mulheres}

Inicialmente, procurou-se conhecer em que medida as pontuações dos participantes difeririam quando comparados os dois tipos de sexismo: hostil $v$ s. benévolo. Neste sentido, foram consideradas tanto a amostra total $(n=301)$ como as específicas de homens $(n=138)$ e mulheres $(n=163)$. As informações a respeito são apresentadas na Tabela 1 a seguir.

Como é possível observar na Tabela 1, a média de sexismo benévolo $(m=38,1)$ foi estatisticamente superior a de sexismo 
hostil $(m=34,6)$ na amostra total, $t(299)=7,47 ; p<0,001$. Este padrão se manteve com independência do sexo do participante. Especificamente, aqueles do sexo masculino pontuaram mais alto em sexismo benévolo $(m=38,8)$ do que em hostil $(m=36,9)$ $[t(136)=2,78 ; p<0,01]$; do mesmo modo, os do sexo feminino apresentaram maior média em sexismo benévolo $(m=37,6)$ do que em hostil $(m=32,7)[t(163)=7,77 ; p<0,001]$. Apesar da diferença nas pontuações de sexismo hostil e benévolo em função das amostras, consonante com a hipótese 1, observou-se que estas estavam direta e significativamente correlacionadas entre si, com um $r$ médio de 0,32 ( $<<0,001)$, evidenciando que compreendem duas facetas de um mesmo construto: sexismo.

Finalmente, as pontuações de homens e mulheres foram comparadas entre si segundo o tipo de sexismo. No caso do sexismo benévolo, não houve diferença estatisticamente significativa $[t(299)=1,47 ; p>0,05]$. Contrariamente, estes grupos apresentaram médias diferentes em relação ao sexismo hostil $[t(298)=5,75 ; p<0,001]$; concretamente, os homens pontuaram mais alto $(m=36,9)$ do que as mulheres $(m=32,7)$. Portanto, corrobora-se a hipótese 2.

\section{Sexismo, Religião, Classe Social e Escolarização}

Embora não tenham sido encontrados estudos brasileiros sobre a influência de variáveis de natureza sócio-demográfica em relação ao sexismo, a obtenção de tais dados sugeriu sua comprovação. Todas as comparações efetuadas são apresentadas na Tabela 2.

Inicialmente, efetuou-se uma $A N O V A$ (teste post hocde_Bonferroni), considerando como variável antecedente a religião dos participantes. No caso do sexismo hostil, comprovou-se uma diferença unicamente entre os que indicaram não ter religião $(m=32,4 ; \phi p=5,78)$ e os católicos $(m=35,1 ; d p=6,59)$, sendo estes mais sexistas hostis, $F(3,296)=2,95$; $p=0,03$. Um padrão equivalente foi observado para o sexismo benévolo,

Tabela 1

Comparacão dos Sexismos Hostil e Benévolo em Função da Amostra (n=301)

\begin{tabular}{lcccccc}
\hline & \multicolumn{4}{c}{ Amostra } \\
\multicolumn{2}{c}{ Total } & \multicolumn{2}{c}{ Homens } & \multicolumn{2}{c}{ Mulheres } \\
\hline Tipo de sexismo & $m$ & $d p$ & $m$ & $d p$ & $m$ & $d p$ \\
Benévolo & 38,1 & 7,53 & 38,8 & 7,21 & 37,6 & 7,76 \\
Hostil & 34,6 & 6,58 & 36,9 & 6,50 & 32,7 & 6,05 \\
$t$ & \multicolumn{2}{c}{7,47} & \multicolumn{2}{c}{2,78} & \multicolumn{2}{c}{7,77} \\
$g l$ & 299 & \multicolumn{2}{c}{136} & \multicolumn{2}{c}{163} \\
$p$ & 0,00 & \multicolumn{2}{c}{0,006} & 0,00 \\
\hline
\end{tabular}

Tabela 2

Os Sexismos Hostil e Benévolo e as Variáveis Sócio-Demográficas

\begin{tabular}{|c|c|c|c|c|}
\hline & \multicolumn{3}{|c|}{ Sexismo } & \\
\hline & \multicolumn{2}{|c|}{ Hostil } & \multicolumn{2}{|c|}{ Benévolo } \\
\hline & $m$ & $d p$ & $m$ & $d p$ \\
\hline \multicolumn{5}{|l|}{ Religião } \\
\hline sem religião & 32,4 & 5,78 & 32,5 & 7,20 \\
\hline Católica & 35,1 & 6,59 & 39,6 & 6,59 \\
\hline evangélica & 35,4 & 7,14 & 41,0 & 7,40 \\
\hline \multirow[t]{2}{*}{ Outra } & 35,4 & 6,73 & 38,1 & 7,95 \\
\hline & \multicolumn{2}{|c|}{$\begin{array}{c}F(3,296)=2,95 \\
p=0,03\end{array}$} & \multicolumn{2}{|c|}{$\begin{array}{c}F(3,297)=18,75 \\
p=0,000\end{array}$} \\
\hline \multicolumn{5}{|l|}{ Classe Social } \\
\hline baixa & 33,3 & 6,25 & 39,1 & 7,11 \\
\hline média & 35,2 & 6,34 & 39,3 & 7,81 \\
\hline \multirow[t]{3}{*}{ alta } & 35,0 & 7,00 & 36,2 & 7,27 \\
\hline & \multirow{2}{*}{\multicolumn{2}{|c|}{$\begin{array}{l}F(2,297)=2,44 \\
\quad p=0,09\end{array}$}} & \multirow{2}{*}{\multicolumn{2}{|c|}{$\begin{array}{c}F(2,298)=5,85 \\
p<0,03\end{array}$}} \\
\hline & & & & \\
\hline \multirow{3}{*}{$\begin{array}{l}\text { Situação Escolar } \\
\text { estuda } \\
\text { não estuda }\end{array}$} & \multirow{5}{*}{\multicolumn{2}{|c|}{$\begin{array}{c}34,5 \quad 6,51 \\
34,7 \quad 6,69 \\
t(298)=0,36 \\
p=0,72\end{array}$}} & \multirow{3}{*}{$\begin{array}{l}37,2 \\
39,4\end{array}$} & \multirow[b]{2}{*}{7,38} \\
\hline & & & & \\
\hline & & & & 7,62 \\
\hline & & & & $=2,47$ \\
\hline & & & & \\
\hline \multirow{5}{*}{$\begin{array}{l}\text { Escolaridade } \\
\text { fundamental } \\
\text { médio } \\
\text { superior }\end{array}$} & & & & \\
\hline & 35,2 & 6,12 & 42,8 & 5,97 \\
\hline & 35,1 & 5,63 & 39,0 & 7,10 \\
\hline & 34,2 & 7,19 & 36,6 & 7,66 \\
\hline & \multicolumn{2}{|c|}{$\begin{array}{l}F(2,296)=0,69 \\
p=0,50\end{array}$} & \multicolumn{2}{|c|}{$\begin{array}{c}F(2,297)=12,00 \\
p<0,000\end{array}$} \\
\hline
\end{tabular}


com os participantes que se declararam como não tendo uma religião apresentando menor média de sexismo $(m=32,5 ; d p=7,20)$ do que aqueles que indicaram ser católicos $(m=39,6 ; d p=6,59)$, evangélicos ( $m=41,0 ; d p=7,40)$ ou ter outra religião $(m=38,1 ; \alpha p=7,95)$.

Em relação à classe social, efetuou-se também uma $A N O V A$. De acordo com esta análise estatística, enquanto no caso do sexismo hostil não foi observada diferença estatisticamente significativa $[F(2,297)=2,44 ; p=0,09]$, esta foi evidente para o sexismo benévolo $[F(2,298)=5,85 ; p<0,01]$. Analisando a Tabela 2, pode-se observar que, segundo o teste de Bonferroni, os participantes classificados como sendo da classe social baixa apresentaram uma pontuação $(m=39,1 ; d p=7,11)$ superior a daqueles classificados como da alta $(m=36,2 ; d p=7,27)$. Estes também apresentaram menor pontuação do que aqueles de classe média ( $m=39,3 ; d p=7,81)$.

Finalmente, no tocante à escolarização, consideraram-se duas variáveis específicas: se o participante estudava e o seu grau de escolaridade. Para a primeira variável, um teste $t$ para amostras independentes foi computado. Este revelou que o fato de estudar (ou não) não afetou o grau de sexismo hostil dos participantes; porém, sim o fez em relação ao sexismo benévolo [ $(299)=2,47 ; p<0,01]$, com os participantes que estudam apresentando uma menor média deste tipo de sexismo $(m=37,2 ; d p=7,38)$ do que os que indicaram não estudar ( $m=39,4 ; d p=7,62)$. Quanto ao grau de escolaridade, foi possível observar que os indivíduos com menor escolaridade (estudos equivalentes ao ensino fundamental) obtiveram maior pontuação no fator sexismo benévolo ( $m=42,8 ; d p=5,97)$ do que o fizeram aqueles com maior escolaridade, isto é, que tinham concluído (ou cursavam) o ensino médio ( $m=39,0 ; \not p=7,10)$ ou o superior ( $m=36,6 ; \phi p=7,66$ ); entre estes últimos também se constatou uma diferença significativa (Bonferroni), $F(2,297)=12,00 ; p<0,000$. No caso do sexismo hostil, nenhuma diferença foi observada em função da escolaridade dos participantes $[F(2,296)=0,69 ; p=0,50]$.

\section{Correlação do Sexismo com os Valores Humanos}

Considerando o objetivo principal do presente estudo de conhecer a relação dos valores humanos com o sexismo ambivalente, foram efetuados os cálculos de correlação parcial entre estes

Tabela 3

Correlacão entre Valores Humanos e Sexismos Hostil e Benévolo

\begin{tabular}{|c|c|c|c|c|c|}
\hline & mo & $d p$ & $\begin{array}{l}\text { Sexismo } \\
\text { total }\end{array}$ & hostil & benévolo \\
\hline \multicolumn{6}{|c|}{ VALORES PESSOAIS } \\
\hline Experimentação & 4,9 & 0,95 & $-0,12^{*}$ & $-0,01$ & $-0,20 * * *$ \\
\hline Emoção & 3,5 & 2,04 & $-0,08$ & $-0,02$ & $-0,12^{*}$ \\
\hline Prazer & 5,5 & 1,52 & $-0,07$ & $-0,01$ & $-0,12$ \\
\hline Estimulação & 5,0 & 1,41 & $-0,08$ & $-0,05$ & $-0,09$ \\
\hline Sexual & 5,5 & 1,39 & $-0,01$ & 0,05 & $-0,07$ \\
\hline Realização & 4,9 & 0,85 & 0,03 & 0,05 & $-0,01$ \\
\hline Autodireção & 5,7 & 1,58 & $-0,22 * * *$ & $-0,15^{* *}$ & $-0,21 * * *$ \\
\hline Prestígio & 4,0 & 2,26 & 0,08 & 0,05 & 0,08 \\
\hline Poder & 3,2 & 2,09 & $0,10^{*}$ & 0,09 & 0,06 \\
\hline Privacidade & 5,9 & 1,36 & 0,01 & 0,04 & $-0,06$ \\
\hline Exxito & 5,7 & 1,25 & 0,05 & 0,05 & 0,03 \\
\hline \multicolumn{6}{|c|}{ VALORES CENTRAIS } \\
\hline Existência & 6,2 & 0,84 & 0,03 & $-0,04$ & 0,09 \\
\hline Estabilidade Pessoal & 6,0 & 1,19 & $0,11 *$ & 0,02 & $0,16^{* *}$ \\
\hline Sobrevivência & 6,3 & 1,07 & 0,03 & $-0,03$ & 0,08 \\
\hline Saúde & 6,3 & 1,08 & $-0,07$ & $-0,06$ & $-0,07$ \\
\hline Suprapessoal & 5,7 & 0,84 & $-0,14 * *$ & $-0,06$ & $-0,17 * *$ \\
\hline Beleza & 4,4 & 1,94 & $-0,15^{* *}$ & $-0,01$ & $-0,16^{* *}$ \\
\hline Conhecimento & 5,6 & 1,28 & $-0,05$ & 0,06 & $-0,14^{*}$ \\
\hline Maturidade & 6,2 & 1,06 & $-0,04$ & $-0,05$ & $-0,02$ \\
\hline Justiça Social & 6,6 & 1,16 & $-0,01$ & $-0,01$ & 0,02 \\
\hline \multicolumn{6}{|l|}{ VALORES SOCIAIS } \\
\hline Interacional & 5,9 & 0,79 & 0,06 & 0,01 & 0,10 \\
\hline Afetividade & 6,3 & 1,16 & 0,05 & $-0,01$ & 0,09 \\
\hline Convivência & 5,0 & 1,57 & 0,01 & $-0,03$ & 0,05 \\
\hline Apoio social & 5,9 & 1,05 & 0,02 & 0,00 & 0,02 \\
\hline Honestidade & 6,6 & 1,09 & 0,05 & 0,05 & 0,05 \\
\hline Normativo & 5,6 & 1,10 & $0,13^{* *}$ & 0,03 & $0,21 * * *$ \\
\hline Obediência & 5,9 & 1,28 & $0,17 * * *$ & $0,12^{*}$ & $0,16^{* *}$ \\
\hline Religiosidade & 6,1 & 2,03 & 0,08 & $-0,03$ & $0,19 * *$ \\
\hline Tradição & 4,1 & 2,09 & 0,06 & 0,01 & 0,10 \\
\hline Ordem Social & 6,1 & 1,24 & $-0,01$ & $-0,00$ & $-0,01$ \\
\hline
\end{tabular}

Notas: $* p<0,05 ; * * p<0,01 ; * * * p<0,001$ (teste uni-caudal; eliminação pairwise de itens sem resposta). 
construtos, tendo como variável controlada a pontuação total dos valores. Os resultados são apresentados na Tabela 3.

Inicialmente é preciso ter em conta as duas últimas hipóteses formuladas. Os resultados a respeito podem ser vistos na terceira coluna desta tabela. A terceira hipótese previa que a pontuação total de sexismo estaria diretamente correlacionada com a função psicossocial normativa, o que foi plenamente corroborado $(r=0,13$; $p<0,01)$. Entre os valores desta função, destaca-se a contribuição de obediência, com o maior coeficiente de correlação $(r=0,17$; $p<0,001)$. No caso da quarta hipótese, esperava-se que o sexismo total se correlacionasse inversamente com a função psicossocial suprapessoal, o que também ocorreu ( $r=-0,14 ; p<0,01)$; entre os valores específicos desta função, a maior correlação foi observada para beleza $(r=-0,15 ; p<0,01)$. Quanto aos demais valores humanos, cabe assinalar a correlação inversa do sexismo com autodireção $(r=-0,22 ; p<0,001)$. Sua correlação foi significativa, porém fraca, com a função psicossocial de experimentação $(r=-0,12 ; p<0,05)$ e com os valores específicos estabilidade pessoal $(r=0,11 ; p<0,05)$ e poder $(r=0,10 ; p<0,05)$.

Embora não tenham sido formuladas hipóteses específicas sobre os dois tipos de sexismo, isto é, o hostil e o benévolo, são também apresentados na Tabela 3 os resultados sobre sua correlação com os valores humanos. No caso do sexismo hostil, este unicamente se correlacionou com os valores autodireção $(r=-0,15 ; p<0,001)$ e obediência $(r=0,12 ; p<0,05)$. No que se refere ao sexismo benévolo, correlacionou-se com as funções psicossociais de experimentação $(r=-0,20 ; p<0,001)$, suprapessoal $(r=-0,17 ; p<0,01)$ e normativa $(r=0,21 ; p<0,001)$, e também com os seguintes valores específicos: autodireção $(r=-0,21 ; p<0,001)$, religiosidade $(r=0,19 ; p<0,01)$, obediência, estabilidade pessoal $(r=0,16 ; p<0,01$; para ambos), beleza $(r=-0,16 ; p<0,01)$, conhecimento $(r=-0,14 ; p<0,05)$ e emoção $(r=-0,12 ; p<0,05)$.

\section{Discussão}

O sexismo ambivalente diz respeito a um conjunto de avaliações negativas e atos discriminatórios dirigidos à mulher, em função de sua condição de gênero (Ferreira, 2000; Glick \& Fiske, 1996). Através de suas faces hostil e benévola, o sexismo ambivalente reflete uma forma de estereótipo construída, aceita e perpetuada por ambos os sexos no contexto social. Portanto, diz respeito a um problema social bastante presente, sobretudo em culturas mais patriarcalistas. Neste contexto, justificou-se o presente estudo, cujo objetivo principal foi conhecer a correlação do sexismo com os valores humanos. Esperase que este tenha sido cumprido. Não obstante, cabe reconhecer uma possível limitação deste estudo: a composição da amostra. Embora tenha o mérito de contar com pessoas da população geral, não se limitando a grupos restritos de participantes (Ex.: estudantes universitários, empregados de organizações), consideraram-se tamanhos diferentes das amostras de homens e mulheres. Além do mais, não é possível de antemão generalizar os resultados aqui apresentados, pois não se pretendeu definir uma amostra representativa da população alvo. Apesar disso, a coerência dos resultados aqui descritos permite pensar na adequação deste estudo. A propósito, exige-se discutir alguns aspectos fundamentais, tratados a seguir.

\section{Sexismo Ambivalente e Características Sócio-Demográficas}

A primeira hipótese do estudo estabeleceu que os dois tipos de sexismo, o hostil e o benévolo, estariam diretamente correlacionados entre si. Isso foi exatamente o que se observou. Esta possibilidade parece bastante clara no modelo teórico de Glick e Fiske (1996), Glick e colaboradores (2000). Embora retratem diferentes idéias, compreendendo duas formas de expressão de preconceito em relação às mulheres, assentam-se na mesma rotulação ou disposição subjetiva de desvalorização da mulher, procurando impor a noção da superioridade masculina.

Seria possivel pensar estas "ideologias" sexistas em termos de duas formas conhecidas de preconceito (Martínez, 1996): tradicional (hostil) e moderna (benévola), que expressam noções bastante propagadas e concomitantes na cultura brasileira. Porém, devido ao caráter mais direto e flagrante do primeiro tipo, parece mais provável que o segundo se torne cada dia mais recorrente. Isso parece coerente com o resultado de os participantes deste estudo, independentemente do sexo, apresentarem-se como mais sexistas benévolos. Apesar deste achado, previa-se que os homens apresentariam maior pontuação em sexismo hostil do que as mulheres. Esta foi a segunda hipótese, que também se confirmou. A razão, como já foi indicada na introdução, parece evidente: as mulheres não poderiam aceitar como justificável uma avaliação negativa flagrante. Assim, rejeitam-na mais veementemente do que o fazem os homens, que obtêm benefícios econômicos e sociais com a depreciação das mulheres.

Além da variável sexo dos participantes, consideraram-se também sua religião, classe social e escolarização. Nenhuma hipótese foi formulada a respeito. No conjunto, estas variáveis podem refletir dois tipos de mentalidade (Rokeach, 1973; Triandis, 1996): aberta (maior escolaridade, classe social elevada e sem religião) vs. fechada (menor escolaridade, classe social baixa e religião tradicional). As pessoas com uma mente aberta são mais prováveis de não apresentar padrões de atitudes, crenças e condutas preconceituosas e sexistas, enquanto que as de mente fechada o fariam em maior medida. Estes foram exatamente os padrões observados, isto é, os participantes católicos e protestantes, sem estudo ou com estudo fundamental e de classe social baixa se mostraram mais sexistas, especialmente sexistas benévolos. Cabe, todavia, lembrar que estes resultados não podem ser plenamente generalizados. Como dito no começo, este é um estudo com uma amostra limitada e pode ser que estas variáveis interajam entre si. Neste sentido, estudos futuros são necessários a respeito, inclusive incorporando medidas diretas dos dois tipos de mentalidade aqui levantados.

\section{Sexismo Ambivalente e Valores Humanos}

Duas hipóteses foram formuladas sobre a relação destes construtos: a primeira estabeleceu que os valores normativos se correlacionariam diretamente com a pontuação total do sexismo, ao passo que os suprapessoais o fariam inversamente. Estas hipóteses foram também corroboradas, indicando de certo modo um apoio aos resultados antes descritos. O conservadorismo, refletido principalmente através dos valores obediência e religiosidade, promove o sexismo, enquanto o universalismo, representado especialmente pelos valores beleza e conhecimento, o inibe (Heaven \& Oxman, 1999; Vera \& Martínez, 1994). Esta situação ficou mais evidente quando se consideraram dois valores específicos: obediência 
vs. autodireção. Embora este último pertença à função psicossocial de realização, não resta dúvida de que reflete a concepção de mente aberta, previamente retratada. Estes foram os valores mais importantes para explicar tanto o sexismo total como os tipos específicos: hostil e benévolo. Esta parece ser uma questão de incorporar vs. não se submeter os padrões culturais convencionais; aqueles que os incorporam e, portanto, assumem os valores mais tradicionais, tenderiam a ser mais sexistas. Este aspecto precisa ser melhor compreendido em estudos futuros, considerando a possibilidade de pesquisas trans-culturais que envolvam países tradicionais (materialistas, coletivistas) e modernos (pós-materialistas, individualistas).

A correlação do sexismo ambivalente com os valores precisa levar em conta o tipo de sexismo. Como foi possível observar na Tabela 2, enquanto unicamente os valores específicos autodireção $(-)$ e obediência $(+)$ se correlacionaram com o sexismo hostil, até sete valores o fizeram com o sexismo benévolo: emoção (-), autodireção $(-)$, beleza $(-)$, conhecimento $(-)$, estabilidade pessoal $(+)$, obediência $(+)$ e religiosidade (+). É possível que este resultado se deva a uma menor variabilidade na pontuação do sexismo hostil; porém, cabe assinalar como uma explicação alternativa a natureza do sexismo benévolo. Este acentua uma visão das mulheres como seres frágeis, que necessitam de atenção, que precisam ser protegidas e que, por serem delicadas, devem ficar em casa e cuidar do lar e dos filhos. $\mathrm{Na}$ cultura brasileira, pelo menos no contexto paraibano, este tipo de manifestação de preconceito é bem consonante com os padrões valorativos tradicionais, com ênfase nas relações interpessoais. Por exemplo, os paraibanos dão mais ênfase aos valores religiosidade, tradição e pertença do que fazem os brasilienses e paulistanos (Gouveia, 1998).

Finalmente, o panorama atual permite concluir que mesmo diante de conquistas evidentes por parte das mulheres, segue sendo notável a sua situação de grupo minoritário, objeto de preconceito. Embora não foram encontrados dados prévios sobre o índice de sexismo sofrido por estas no Brasil, muito provavelmente em muito pouco houve mudança. $\mathrm{O}$ mais provável é que, devido às leis cada dia mais claras e punitivas contra todo tipo de discriminação, o sexismo venha assumindo uma cara mais benévola, porém não menos discriminativa. As pesquisas futuras deveriam explorar este aspecto, incorporando a possibilidade de medidas sobre as causas e conseqüências do sexismo. Por exemplo, poderia ser avaliado o quanto a multiplicidade de papéis assumido pelas mulheres contribuiria para explicar seu engajamento em atitudes sexistas, sejam hostis ou benévolas. Poderia ainda ser considerada uma avaliação do quanto à mulher pensa que sofre de discriminação devido ao seu gênero e em que medida isso estaria correlacionado com indicadores de satisfação com a vida e saúde mental. Além disto, poderia também se analisar a relação dos sexistas ambivalentes com o desejo de apresentar condutas julgadas positivamente pelo grupo social no qual está inserido.

\section{Referências}

Agacinski, S. (1999). Politica dos sexos. Rio de Janeiro: Nova Fronteira.

Borgida, E., Locksley, A. \& Brekke, N. (1981). Social stereotypes and judgment. Em N. Cantor \& J. F. Kihlstrom (Org.), Personality, cognition and social interaction (pp. 153162). New Jersey: Lawrence Erlbaum.

Camino, L. (1996). Conbecimento do outro e a construşão da realidade social: Uma análise da percepscão e da cognição social (Série monografias em Psicologia Social). João Pessoa: Editora Universitária.

Castells, M. (2000). Opoder da identidade. São Paulo: Paz e Terra.

Ferreira, M. C. (2000, outubro). Sexismo hostil e benevolente: Interrelações e diferenças de gênero. Trabalho apresentado na XXX Reunião Anual da Sociedade Brasileira de Psicologia, Brasilia, DF.

Formiga, N. S., Gouveia, V. V., Maia, L. \& Santos, M. N. (2002). Inventário de Sexismo Ambivalente: Sua adaptação e relação com o gênero. Psicologia em Estudo, 7, 103-111.

Glick, P., Diebold, J., Bailey-Werner, B. \& Zhu, L. (1997). The two faces of Adam: Ambivalent sexism and polarized attitudes toward women. Personality and Social Psychology Bulletin, 23, 1323-1334.

Glick, P. \& Fiske, S. T. (1996). The Ambivalent Sexism Inventory: Differentiating hostile and benevolent sexism. Journal of Personality and Social Psychology, 70, 491-512.

Glick, P., Fiske, S. T., Mladinic, A., Saiz, J.L., Abrams, D., Masser, B., Adetoun, B., Osagie, J.E., Akande, A., Alao, A., Brunner, A., Willemsen, T. M., Chipeta, K., Dardenne, B, Dijksterhuis, A., Wigboldus, D., Eckes, T., Six-Materna, I., Exposito, F., Moya, M., Foddy, M., Kim, H., Lameiras, M., Sotelo, M. J., Mucchi-Faina, A., Romani, M., Sakalli, N., Udegbe, B., Yamamoto, M. Ui, M., Ferreira, M. C. \& López, W. L. (2000). Beyond prejudice as simple antipathy: Hostile and benevolent sexism across cultures. Journal of Personality and Social Psychology, 79, 763-775.

Glick, P. \& Fiske, S. T. (2001a). Ambivalent sexism. Advances in Experimental Social Psychology, 33,115-188.

Glick, P. \& Fiske, S. T. (2001b). An ambivalent alliance: Hostile and benevolent sexism a complementary justifications of gender inequality. American Psychologist, 56, 109118.

Gouveia, V. V. (1998). L a naturaleza de los valores descriptores del individualismo y del colectivismo: Una comparación intra e intercultural. Tese de Doutorado não-publicada, Faculdade de Psicologia, Universidade Complutense de Madri. Madri, Espanha.

Heaven, P. C. L. \& Oxman, L. N. (1999). Human values, conservatism and stereotypes of homosexuals. Personality and Individual Differences, 27, 109-118.

Heilborn, M. L. (1999). Sexualidade: Olhar das Cièncias Sociais. Rio de Janeiro: Zahar.

Lopes de Andrade, M. W. C. (2001). A dimensão valorativa do sentido da vida. Dissertação de Mestrado não-publicada, Departamento de Psicologia, Universidade Federal da Paraiba. João Pessoa, PB.

Maia, L. M. (2000). Prioridades valorativas e desenvolvimento moral: Considerações acerra de uma teoria dos valores humanos. Dissertação de Mestrado não-publicada, Departamento de Psicologia, Universidade Federal da Paraiba. João Pessoa, PB.

Martínez, M. C. (1996). Análisispssicosocial del prejuicio. Madri: Editorial Síntesis.

Maslow, A. H. (1954/1970). Motivacion and personality. New York: Harper \& Row.

Molpeceres, M. A. (1994). El sistema de valores: Su configuración cultural y su socialización familiar en la adolescencia. Tese de Doutorado não-publicada, Faculdade de Psicologia, Universidade de Valência. Valência, Espanha.

Rokeach, M. (1973). The nature of buman values. New York: The Free Press.

Schwartz, S. H. (2001). Existen aspectos universales en la estructura y el contenido de los valores humanos? Em M. Ros \& V. V. Gouveia (Orgs.), Psicologia social de los valores bumanos: Desarrollos teóricos, metodológicos y aplicados (pp. 53-77). Madri: Editorial Biblioteca Nueva.

Schwartz, S. H. \& Bilsky, W. (1987). Toward a universal psychological structure of humanian values. Journal of Personality and Social Psychology, 53, 550-562.

Schwartz, S. H. \& Sagiv, L. (1995). Identigying culture-specifics in the content and structure of values. Journal of Cross-Cultural Psychology, 26, 92-116.

Triandis, H. C. (1996). The psychological measurement of cultural syndromes. American Psychologist, 51, 407-415.

Vera,J.J. \& Martínez, M. C. (1994). Preferencia de valores en relación con los prejuicios hacia exogrupos. Anales de Psicologia, 10, 29-40.

Recebido:09/09/2003

$1^{a}$ Revisão: $19 / 11 / 2003$

Aceite Final: 21/01/2004

Sobre os autores

Raquel Pereira Belo é Psicóloga e Mestre em Psicologia pela Universidade Federal da Paraíba e Professora substituta na mesma instituição.

Valdiney V. Gouveia é Mestre pela Univerisdade de Brasilia e Doutor pela Universidad Complutense de Madrid. É Professor da Universidade Federal da Paraíba.

Jorge da Silva Raymundo é Psicólogo, Doutor em Psicologia pela Fundação Getúlio Vargas e Professor do Curso de Pós-Graduação em Psicologia da Universidade Federal da Paraiba.

Célia Maria Cruz Marques é Psicóloga e Mestre pela Universidade Federal da Paraíba.

Psicologia: Reflexão e Crítica, 2005, 18(1), pp.7-15 